\title{
Demultiplexing of OTDM-DPSK signals based on a single semiconductor optical amplifier and optical filtering
}

Xu, Jing; Ding, Yunhong; Peucheret, Christophe; Seoane, Jorge; Mulvad, Hans Christian Hansen; Galili, Michael; Xue, Weiqi; Mørk, Jesper; Jeppesen, Palle

Published in:
Optics Letters

Link to article, DOI:

10.1364/OL.36.001560

Publication date:

2011

Document Version

Publisher's PDF, also known as Version of record

Link back to DTU Orbit

Citation (APA):

Xu, J., Ding, Y., Peucheret, C., Seoane, J., Mulvad, H. C. H., Galili, M., Xue, W., Mørk, J., \& Jeppesen, P. (2011). Demultiplexing of OTDM-DPSK signals based on a single semiconductor optical amplifier and optical filtering. Optics Letters, 36(9), 1560-1562. https://doi.org/10.1364/OL.36.001560

\section{General rights}

Copyright and moral rights for the publications made accessible in the public portal are retained by the authors and/or other copyright owners and it is a condition of accessing publications that users recognise and abide by the legal requirements associated with these rights.

- Users may download and print one copy of any publication from the public portal for the purpose of private study or research.

- You may not further distribute the material or use it for any profit-making activity or commercial gain

- You may freely distribute the URL identifying the publication in the public portal 


\title{
Demultiplexing of OTDM-DPSK signals based on a single semiconductor optical amplifier and optical filtering
}

\author{
Jing Xu, ${ }^{1, *}$ Yunhong Ding, ${ }^{1,2}$ Christophe Peucheret, ${ }^{1}$ Jorge Seoane, ${ }^{1}$ Hans Christian Hansen Mulvad, ${ }^{1}$ \\ Michael Galili, ${ }^{1}$ Weiqi Xue, ${ }^{1}$ Jesper Mørk, ${ }^{1}$ and Palle Jeppesen ${ }^{1}$ \\ ${ }^{1}$ DTU Fotonik, Department of Photonics Engineering, Technical University of Denmark, DK-280o Kgs. Lyngby, Denmark \\ ${ }^{2}$ Wuhan National Laboratory for Optoelectronics, Huazhong University of Science and Technology, Wuhan, 430074, China \\ ${ }^{*}$ Corresponding author: jinxu@fotonik.dtu.dk
}

Received January 5, 2011; revised March 22, 2011; accepted March 28, 2011; posted March 31, 2011 (Doc. ID 140681); published April 21, 2011

\begin{abstract}
We propose and demonstrate the use of a single semiconductor optical amplifier (SOA) and optical filtering to time demultiplex tributaries from an optical time division multiplexing-differential phase shift keying (OTDM-DPSK) signal. The scheme takes advantage of the fact that phase variations added to the target channel by cross-phase modulation from the control signal are effectively subtracted in the differential demodulation scheme employed for DPSK signals. Demultiplexing from 80 to $40 \mathrm{Gbit} / \mathrm{s}$ is demonstrated with moderate power penalty using an SOA with recovery time twice as long as the bit period at $80 \mathrm{Gbit} / \mathrm{s}$. Large dynamic ranges for the input power and SOA current are experimentally demonstrated. The scheme is expected to be scalable toward higher bit rates. (c) 2011 Optical Society of America
\end{abstract}

OCIS codes: $070.4340,250.5980$.

Optical time division multiplexing (OTDM) systems allow generation, transmission, processing, and detection of serial data rates far beyond the speed limit set by electronics [1]. Detection of OTDM signals is usually performed by first extracting the lower speed tributaries from the signal, i.e., demultiplexing from the aggregate rate to the base rate, using high-speed optical switches [2-4]. An ultrafast photonic switch based on an SOA, i.e., an SOA followed by optical filters, has been demonstrated for $640 \mathrm{Gbit} / \mathrm{s}$ optical time demultiplexing using an SOA with recovery time larger than $8 \mathrm{ps}$ [4]. The scheme can be traced back to interferometric structures $[\underline{5}, \underline{6}]$ and benefits from the fact that the slow recovery process can be effectively equalized by making use of new frequency components of the probe spectrum generated in the SOA [7]. The scheme is also very attractive thanks to its simple structure, improved stability compared to fiber-based solutions, possibility of integration, and low switching power.

The use of phase modulation, such as DPSK, has recently gained favor in OTDM systems thanks to its robustness to transmission impairments [8]. OTDMDPSK demultiplexing has been recently demonstrated using SOA-based interferometric structures, e.g., from 80 to $10 \mathrm{Gbit} / \mathrm{s}$ by placing an SOA (also known as a semiconductor laser amplifier) in a loop mirror [9], and from 640 to $40 \mathrm{Gbit} / \mathrm{s}$ by using a symmetric Mach-Zehnder switch incorporating SOAs [10]. The challenge in demultiplexing phase modulated signals in SOAs is that the phase information must be preserved by the switching process. Thanks to the differential demodulation scheme employed for DPSK signals (typically performed in a Mach-Zehnder delay interferometer), any periodic phase variation at the base rate added to the target channel due to cross-phase modulation (XPM) in the SOA can be effectively cancelled out. While for on-off-keying (OOK) signal demultiplexing, interferometric structures have evolved into the much simpler configuration of an SOA followed by offset filtering [7], it remains to be ver- ified that demultiplexing of OTDM-DPSK signals can also be achieved using this simpler scheme.

In this work, we demonstrate for the first time (to our knowledge) 80 to $40 \mathrm{Gbit} / \mathrm{s}$ demultiplexing of return-tozero (RZ) DPSK signals based on a single SOA assisted by optical filtering. Error-free operation is achieved for the two $40 \mathrm{Gbit} / \mathrm{s}$ tributaries with 3.5 and $5 \mathrm{~dB}$ power penalty. The $1 / e$ recovery time of the SOA is $\sim 25 \mathrm{ps}$, which is twice as long as the bit period at $80 \mathrm{Gbit} / \mathrm{s}$. Thanks to the fact that DPSK signals have identical power in every bit slot, no obvious dependence on the input data pattern length is observed in the experiment.

Figure 1 shows the principle of operation of OTDMDPSK switching based on a single SOA followed by offset filtering. When a weak probe signal copropagates in an SOA with a strong pulsed pump signal, the probe will be chirped by the pump due to XPM when the pulses are temporally aligned. By placing a frequency discriminating filter that is detuned from the DPSK center wavelength, the DPSK signal is blocked at the output when there is no pump pulse at the input. However, when a pump pulse is present at the input, it will introduce frequency shifts on the DPSK signal due to XPM. If the filter is detuned properly, part of the frequency-shifted DPSK signal will be transmitted through the filter. Since the strong frequency shifts introduced by the ultrafast dynamics of the SOA occur within the pump pulse duration, high-speed switching windows are formed when the

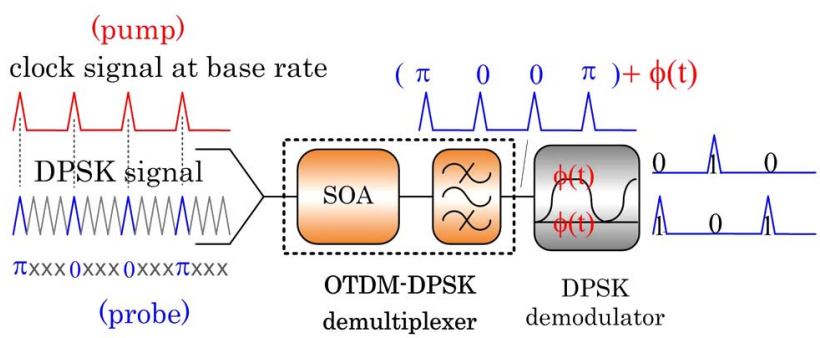

Fig. 1. (Color online) Principle of operation of OTDM-DPSK demultiplexer based on an SOA followed by an optical filter that is detuned from the probe center wavelength. 
pump pulses are present. In the demultiplexing case, a clock signal at the base rate ( $40 \mathrm{GHz}$, in this experiment) acts as the pump signal, while the high-speed OTDMDPSK signal acts as the probe signal. Consequently, a switching window is opened when the clock signal is present, resulting in a single OTDM tributary channel being switched to the output. Because of XPM being introduced by the clock signal, a periodic phase variation at the base rate, $\phi(t)$, is added to the phase of the demultiplexed channel. Since this phase variation is identical for every switched bit, its effect will cancel out at the outputs of the 1 bit delay interferometer used for phase-tointensity conversion of the demultiplexed DPSK signal. It should be noted that since the XPM effect transfers intensity information, but not phase information, to the probe signal, it is very important to use the high-speed OTDM signal as the probe and to carry out offset filtering on the probe spectrum. This is in contrast to [4], where the clock signal was used as the probe signal.

Figure 2 shows the experimental setup for OTDMDPSK demultiplexing. The details of the transmitter are shown in Fig. 2(a). Two pulse trains at different wavelengths are generated from a common short pulse generator, which consists of two continuous-wave lasers centered at 1546 and $1560 \mathrm{~nm}$, a Mach-Zehnder modulator (MZM) used to carve $50 \%$ duty cycle pulses at $40 \mathrm{GHz}$, and a phase modulator followed by a length of standard single mode fiber (SSMF) for pulse compression [11]. The PM is driven by a $40 \mathrm{GHz}$ radio frequency $(\mathrm{RF})$ signal with $V_{\mathrm{pp}}=3 V_{\pi}$, where $V_{\mathrm{pp}}$ is the peak-to-peak voltage of the $\mathrm{RF}$ signal and $V_{\pi}$ is the half-wave voltage of the PM. After transmission through a $380 \mathrm{~m}$ SSMF, two pulse trains having a full width at half-maximum (FWHM) of $4.7 \mathrm{ps}$ and a repetition rate of $40 \mathrm{GHz}$ are obtained. By dividing the output of the pulse generator into two branches and filtering at different wavelengths using $2 \mathrm{~nm}$ bandpass filters (BPFs), the two pulse trains are separated. The pulse train centered at $1560 \mathrm{~nm}$ is used as the clock signal, i.e., the pump, in the demultiplexing process. The pulse train centered at $1546 \mathrm{~nm}$ is sent into a nonlinear pulse compression stage that further com-

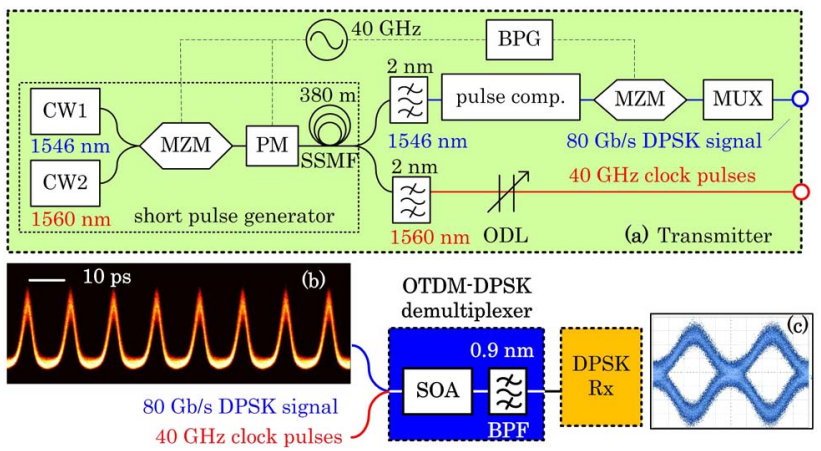

Fig. 2. (Color online) Experimental setup. The OTDM-DPSK demultiplexer is composed of a single SOA followed by a detuned $0.9 \mathrm{~nm}$ optical BPF. (a) Details of the OTDM transmitter (b) $80 \mathrm{Gbit} / \mathrm{s}$ OTDM-DPSK signal generated by the transmitter (c) typical balanced detected eyes at a BER of $10^{-9}$. CW, continuous-wave laser diode; MZM, Mach-Zehnder modulator; PM, phase modulator; SSMF, standard single mode fiber; MUX, optical time division multiplexer; ODL, optical delay line; FBG, fiber Bragg grating.

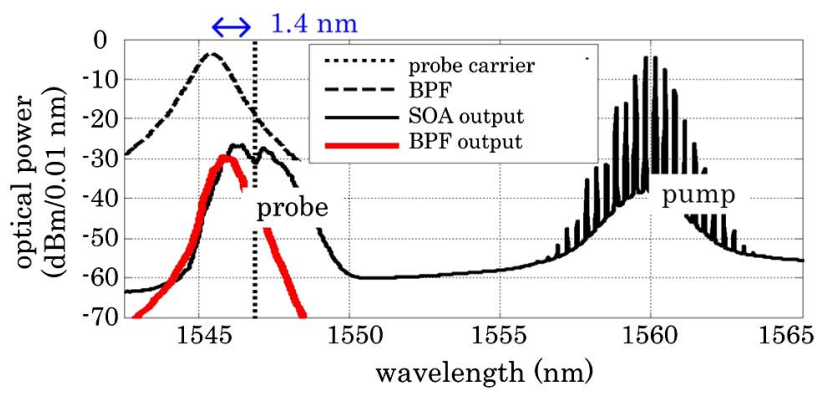

Fig. 3. (Color online) Measured optical spectra at the output of the SOA and after offset filtering of the probe.

presses the signal pulses to $2.5 \mathrm{ps}$. By feeding the pulse train into another MZM driven by a bit pattern generator, a $40 \mathrm{Gbit} / \mathrm{s} \mathrm{RZ-DPSK} \mathrm{signal} \mathrm{is} \mathrm{generated.} \mathrm{An}$ $80 \mathrm{Gbit} / \mathrm{s}$ RZ-DPSK signal, shown in Fig. 2(b), is formed at the output of a 40 to $80 \mathrm{Gbit} / \mathrm{s}$ delay line multiplexer (MUX) and used as the probe signal in the demultiplexing process. The OTDM-DPSK demultiplexer consists of an SOA and a $0.9 \mathrm{~nm} \mathrm{BPF}$. The BPF is a commercially available optical filter with a Lorentzian-type transfer function (as shown by the dashed curve in Fig. 3). The SOA used in the experiment is designed for nonlinear signal processing. It is biased at $400 \mathrm{~mA}$ and exhibits a gain peak at $1560 \mathrm{~nm}$. The typical $1 / e$ recovery time is $\sim 25 \mathrm{ps}$, which is twice as much as the bit period of the $80 \mathrm{Gbit} / \mathrm{s}$ signal. The input power for the pump $(40 \mathrm{GHz}$ clock) and probe ( $80 \mathrm{Gbit} / \mathrm{s}$ RZ-DPSK) signal is $6 \mathrm{dBm}$ and $0 \mathrm{dBm}$, respectively. The demultiplexed $40 \mathrm{Gbit} / \mathrm{s}$ DPSK signal is finally injected into a DPSK receiver consisting of a 1 bit Mach-Zehnder delay interferometer followed by a balanced photodetector with $45 \mathrm{GHz}$ bandwidth. A typical balanced detected eye at a bit error ratio (BER) of $10^{-9}$ is shown in Fig. 2(c).

The measured optical spectra are shown in Fig. 3. The $80 \mathrm{Gbit} / \mathrm{s}$ RZ-DPSK signal and $40 \mathrm{GHz}$ clock signal at the output of the SOA are shown by the solid black curve. The dashed and dotted curves show the transfer function of the $0.9 \mathrm{~nm} \mathrm{BPF}$ and the probe carrier wavelength, respectively, indicating that the BPF is shifted $1.4 \mathrm{~nm}$ to the blue side of the probe center wavelength. The spectrum after the BPF is shown by the thick red curve. Figure 4 shows the measured BER performance of the OTDMDPSK demultiplexer. The length of the used pseudorandom binary sequence (PRBS) is at first $2^{31}-1$ (solid symbols). Note that the MUX is not PRBS preserving

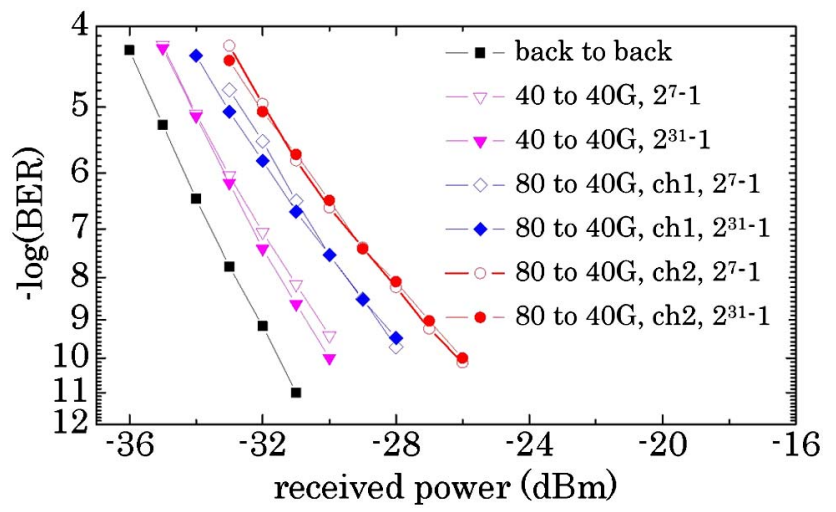

Fig. 4. (Color online) BER performance for $40 \mathrm{Gbit} / \mathrm{s}$ switching and for 80 to $40 \mathrm{Gbit} / \mathrm{s}$ demultiplexing. 

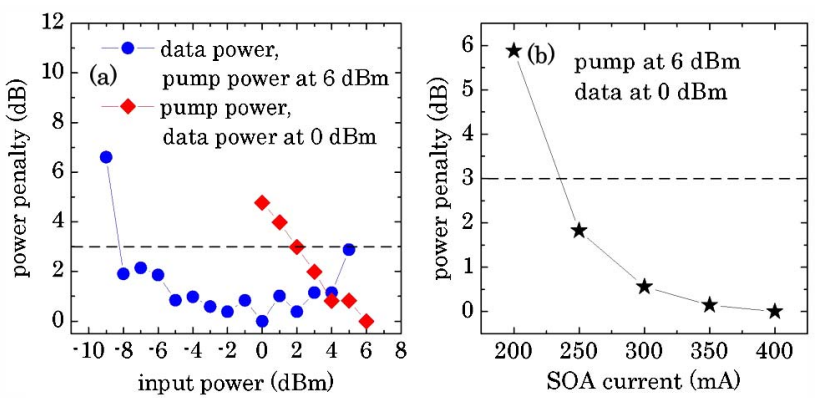

Fig. 5. (Color online) Measurement of the $3 \mathrm{~dB}$ input power dynamics as well as operating current dynamics.

at this PRBS length. Error-free performance is achieved for both demultiplexed channels, with $3.5 \mathrm{~dB}$ (circlesolid) and $5 \mathrm{~dB}$ (diamond-solid) power penalty compared to the back-to-back situation (square). No obvious error floor is observed. The 40 to $40 \mathrm{Gbit} / \mathrm{s}$ switching performance was also measured by blocking one path of the MUX. About $2 \mathrm{~dB}$ power penalty is observed in this case, indicating up to $3 \mathrm{~dB}$ power penalty induced by the cross talk from the neighboring channel. This cross talk is mainly attributed to power leakage of the nontarget channel through the detuned BPF. The cross talk may be improved by creating stronger frequency chirp on the target channel so that the BPF can be tuned further away from the probe center wavelength. No obvious BER variations $(<0.5 \mathrm{~dB})$ were observed when using a shorter PRBS of $2^{7}-1$ (open symbols), showing that the scheme is not sensitive to the input data pattern with the aforementioned limitation that the employed multiplexer is not PRBS preserving. This is in accordance with previous observations on SOA-based demultiplexing of OTDM-DPSK signals [9]. The polarization dependence of the scheme is measured to be lower than $0.5 \mathrm{~dB}$, enabled by the use of a polarization insensitive SOA.

The input power and operating current tolerances of the scheme are further characterized. The reference point is chosen as the optimum operation performance that could be achieved in the experiment, i.e., $6 \mathrm{dBm}$ clock (pump) power, $0 \mathrm{dBm}$ data (probe) power, and $400 \mathrm{~mA}$ operating current. As shown in Fig. 5(a), when the pump power is fixed at $6 \mathrm{dBm}$, the input data power can vary from -8 to $5 \mathrm{dBm}$, while maintaining a power penalty below $3 \mathrm{~dB}$ compared to the optimum situation. When the data power is fixed at $0 \mathrm{dBm}$, the pump power can vary from 2 to $6 \mathrm{dBm}$ with less than $3 \mathrm{~dB}$ power penalty. Further increase of the pump power is prohibited in this experiment in order to avoid damaging the SOA. Figure 5(b) shows the operating current dynamics of the scheme. An operating range larger than $150 \mathrm{~mA}$ is found for the SOA current, while operating within the $3 \mathrm{~dB}$ power penalty limit.
To summarize, we proposed and demonstrated an OTDM-DPSK demultiplexing scheme based on a single SOA assisted by an offset filter. Operation was demonstrated for 80 to $40 \mathrm{Gbit} / \mathrm{s}$ demultiplexing with no visible error floor. Up to $3 \mathrm{~dB}$ cross talk power penalty is observed and mostly ascribed to the power leakage of the nontarget channel from the detuned BPF. Large input power dynamic range (over $13 \mathrm{~dB}$ for the data signal) is achieved. This work demonstrates the suitability of the scheme, already reported for OOK signals, for phase modulated signals. The range of applications of such switches is, therefore, significantly extended for alloptical signal processing of advanced modulation formats. The use of phase modulated signals also alleviates patterning effects of the scheme, which are one of the main drawbacks for SOA-based OOK signal processing [12]. The scheme is expected to be scalable to even higher data rates since the XPM effect can be enhanced by employing shorter pump pulses, which would be necessary when the data symbol rate increases.

This work was supported by Villum Kann Rasmussen Fonden through the Nanophotonics for Terabit Communications (NATEC) center.

\section{References}

1. L. K. Oxenløwe, M. Galili, H. C. H. Mulvad, H. Hu, H. Ji, J. $\mathrm{Xu}$, E. Palushani, J. L. Areal, A. T. Clausen, and P. Jeppesen, in 36th European Conference on Optical Communication (2010), paper Mo.1.A.1.

2. T. Yamamoto, E. Yoshida, and M. Nakazawa, Electron. Lett. 34, 1013 (1998).

3. A. Bogoni, X. Wu, I. Fazal, and A. E. Willner, Opt. Lett. 34, 1825 (2009).

4. E. Tangdiongga, Y. Liu, H. de Waardt, G. D. Khoe, A. M. J. Koonen, H. J. S. Dorren, X. Shu, and I. Bennion, Opt. Lett. 32, 835 (2007).

5. J. P. Sokoloff, P. R. Prucnal, I. Glesk, and M. Kane, IEEE Photon. Technol. Lett. 5, 787 (1993).

6. S. Nakamura, Y. Ueno, K. Tajima, J. Sasaki, T. Sugimoto, T. Kato, T. Shimoda, M. Itoh, H. Hatakeyama, T. Tamanuki, and T. Sasaki, IEEE Photon. Technol. Lett. 12, 425 (2000).

7. M. L. Nielsen and J. Mørk, J. Opt. Soc. Am. B 21, 1606 (2004).

8. A. H. Gnauck and P. J. Winzer, J. Lightwave Technol. 23, 115 (2005).

9. Y.-C. Ku, K. Chan, C.-K. Chan, and L.-K. Chen, in 11th OptoElectronics and Communications Conference (2006), paper 7C1-4-1.

10. T. Hirooka, M. Okazaki, T. Hirano, P. Guan, M. Nakazawa, and S. Nakamura, IEEE Photon. Technol. Lett. 21, 1574 (2009).

11. T. Kobayashi, H. Yao, K. Amano, Y. Fukushima, A. Morimoto, and T. Sueta, IEEE J. Quantum Electron. 24, 382 (1988).

12. J. Xu, X. Zhang, and J. Mørk, IEEE J. Quantum Electron. 46, 87 (2010). 